\title{
The Effects of Hydrodynamic Shear Stress on Fertilization and Early Development of the Purple Sea Urchin Strongylocentrotus purpuratus
}

\author{
KRISTINA S. MEAD AND MARK W. DENNY \\ Department of Biological Sciences, Stanford University, Hopkins Marine Station, \\ Pacific Grove, California 93950
}

\begin{abstract}
Life in the highly turbulent surf zone poses a severe challenge to reproduction in free-spawning animals. Not only can breaking waves quickly dilute the gametes shed by spawning organisms, but turbulence-induced shear stresses may limit fertilization and interfere with normal development. A Couette cell was used to re-create some of the effects of turbulent water motion to study effects of environmentally relevant shear stresses on fertilization in the purple sea urchin (Strongylocentrotus purpuratus). Although low shear stresses improved fertilization success (presumably by increasing mixing), exposure to high shear stresses (of the magnitude found in the surf zone) substantially decreased fertilization success, probably by interfering with contact between egg and sperm. Furthermore, eggs fertilized at high shear stresses often showed abnormal development and low survival of eggs through the blastula stage.
\end{abstract}

\section{Introduction}

Like most intertidal invertebrates, Strongylocentrotus purpuratus, the purple sea urchin, reproduces by means of external fertilization. $S$. purpuratus is commonly found on exposed intertidal rocky shores and in nearshore benthic environments. In both of these habitats, its gametes are subject to the energetic turbulent mixing characteristic of these environments. Although a small amount of turbulence can provide beneficial mixing, bringing eggs and sperm into contact, the intense turbulence of the surf zone or the benthic boundary layer may interfere with fertilization through a variety of mechanisms. These include gamete dilution, gamete damage, decreased en-

Received 28 July 1994; accepted 28 November 1994. counter rate between the egg and the sperm, and removal of the sperm from the egg's surface before fertilization is complete.

To date, the best studied of these mechanisms concerns the effects of gamete dilution. The percentage of eggs fertilized during spawning depends on the local concentration of viable sperm (Vogel et al., 1982, Levitan et al., 1991). When subjected to the type of turbulent flows found commonly in nearshore waters, sperm concentrations can decrease by several orders of magnitude within a meter of a spawning male (Denny, 1988; Denny and Shibata, 1989; Grosberg, 1991), resulting in low rates of fertilization (Pennington, 1985; Levitan et al., 1992). The dilution of sperm increases with an increase in distance downstream from a spawning male and with an increase in current velocity, resulting in a decrease in fertilization (Pennington, 1985; Grosberg, 1987, 1991; Yund, 1990; Petersen, 1991; Petersen et al., 1992; Levitan et al., 1992; Oliver and Babcock, 1992). The detrimental effects of sperm dilution can be partially offset through an increase in the overall number, size, spatial density, synchronicity, and fecundity of spawning animals (Denny and Shibata, 1989; Levitan, 1991; Levitan et al., 1992; Babcock and Mundy, 1992; Sewell and Levitan, 1992; Babcock et al., 1994). Nonetheless, field studies have shown that the fraction of eggs fertilized in the water column is typically low, often less than 15\% (Pennington, 1985; Levitan, 1991; Levitan et al., 1992).

Under certain circumstances, however, gamete dilution may be greatly reduced. Denny and coworkers (1992) showed that the presence of surge channels can drastically reduce the rate of dilution in the surf zone of rocky shores, to the extent that gamete concentrations could locally be high enough to result in efficient fertilization. They tem- 
pered this prediction, however, by noting that gamete dilution is only one of several factors affecting external fertilization and suggested that the effects of small-scale hydrodynamics could impose additional limits to the efficacy of this common form of reproduction.

Here we explore this possibility by recreating in the laboratory one important aspect of turbulent flow (hydrodynamic shear stress) and measuring its effect on fertilization and early development in the common purple sea urchin, $S$. purpuratus. In the next section, we describe the eddy sizes, shear stresses, and energy dissipation rates found in the surf zone. We then discuss how the average values of these parameters make it possible to mimic some aspects of turbulent flow in a rotating device called a Couette cell. Finally, by examining fertilization under a variety of conditions in the Couette cell, we show that surf zone turbulence may have important consequences for both the fertilization and the early development of sea urchin embryos.

\section{Theoretical Background}

\section{Surf-zone turbulence}

When a wave breaks on a rocky shore, its orderly motion is disrupted as the waveform degenerates into a collection of turbulent eddies (Denny, 1988). The interaction of eddies causes the water to be sheared, and the friction between layers of fluid (a result of viscosity) causes a shear stress, $\tau$, to be exerted on the fluid and any gametes in it (Okubo, 1978; Fischer, 1979). As an additional result of friction, the wave's energy is lost to heat at a rate $\epsilon$, called the energy dissipation rate. Shear stress has the units $\mathrm{N} / \mathrm{m}^{2}$, the energy dissipation rate has the units $\mathrm{W} / \mathrm{m}^{3}$, and for a given fluid, the two are related by viscosity:

$$
\epsilon=\tau^{2} / \mu,
$$

where $\mu$ is the dynamic viscosity of seawater at $12^{\circ} \mathrm{C}$, here taken to be $1.24 \times 10^{-3} \mathrm{~Pa} \cdot \mathrm{s}$ (Denny et al., 1992). Shear stress and energy dissipation rate are different descriptors of the same phenomenon: the small-scale deformation of fluid by turbulence.

Rates of energy dissipation, averaged over both time and space, have been predicted for the surf zone (Thornton and Guza, 1983; Svendsen, 1987; Denny et al., 1992; George et al., 1994); $\epsilon$ increases with both wave height and beach slope, with expected values ranging from 10 $3000 \mathrm{~W} / \mathrm{m}^{3}$ on wave-swept rocky shores (Fig. 1). The only direct data for energy dissipation rates in the surf zone come from hotfilm anemometer measurements of the turbulence generated by small waves breaking on the gently sloping beach at Scripps Pier (George et al., 1994). For 1-m-high waves, a time-averaged value of $\epsilon$ of about $10 \mathrm{~W} / \mathrm{m}^{3}$ was measured, with instantaneous values ranging up to $100 \mathrm{~W} / \mathrm{m}^{3}$.

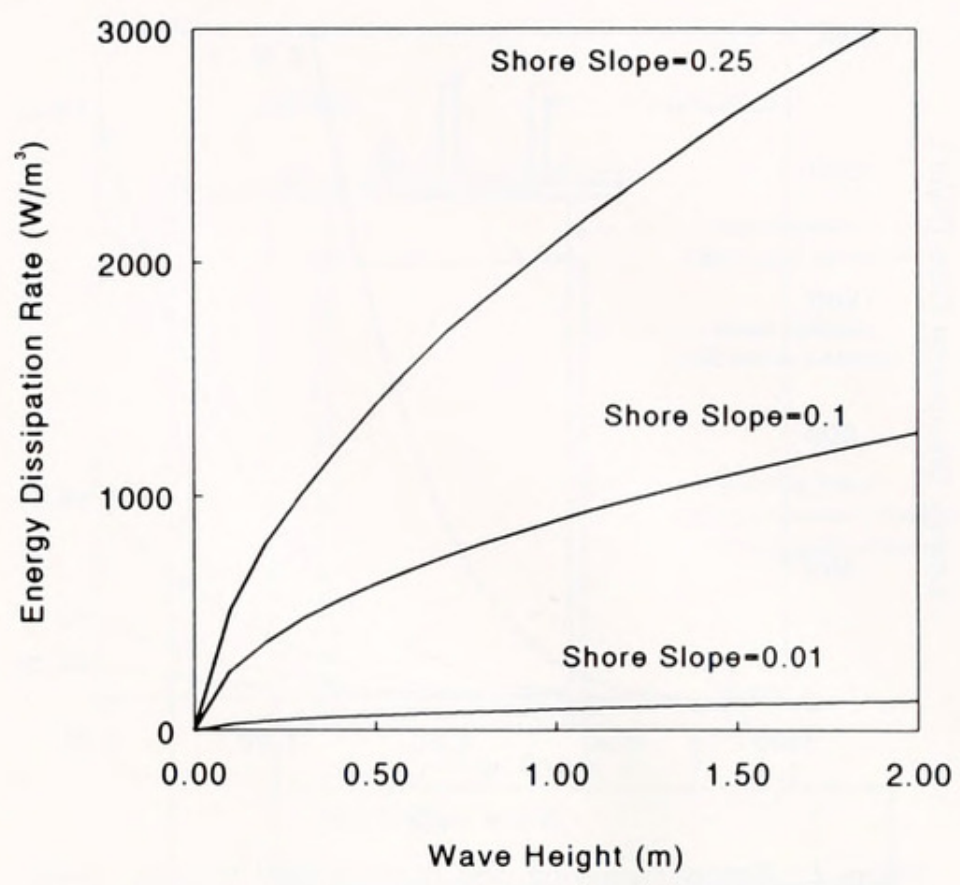

Figure 1. Energy dissipation rates in the surf zone. Predicted values given typical beach slopes and wave heights (Denny et al., 1992).

\section{The benthic boundary layer}

While the intense turbulence characteristic of the surf zone is apparent to an observer, habitats occupied by $S$. purpuratus in the benthic boundary layer near shore also experience high energy dissipation rates. In this case energy is dissipated as water is sheared against the solid substratum. The shear stress exerted on the substratum by turbulent flow is $\rho u_{*}^{2}$, where $\rho$ is the density of the water (about $1025 \mathrm{~kg} / \mathrm{m}^{3}$ for seawater) and $u_{*}$, an index of turbulence intensity, is the friction velocity (Schlichting, 1979). From Equation 1, we see that this shear stress results in an energy dissipation rate of $\rho^{2} u_{*}^{4} / \mu$. The friction velocity for flow over the rough substrata typical of rocky shores is typically $5 \%$ of the mainstream velocity (Middleton and Southard, 1984), which in turn depends on the height and period of the waves and the depth of the water column. Using linear wave theory to estimate mainstream water velocities near the substratum (Denny, 1988), it is thus possible to estimate energy dissipation rates in near-shore benthic boundary layers for a typical wave period of $10 \mathrm{~s}$ (Fig. 2). For the depths and wave heights shown, peak wave-induced velocities vary from 0.02 to $1.35 \mathrm{~m} / \mathrm{s}$, friction velocities from 0.001 to $0.067 \mathrm{~m} / \mathrm{s}$, and peak energy dissipation rates from 0.001 to $17,600 \mathrm{~W} / \mathrm{m}^{3}$ (resulting in average energy dissipation rates of 0.0005 to $8,800 \mathrm{~W} / \mathrm{m}^{3}$ ).

Although energy dissipation rates predicted for the benthic boundary layer can be quite high, their effect is very localized. The thickness of the benthic boundary layer under waves is approximately $0.41 u_{*} T / 2 \pi$, where $T$ is the wave period (Grant and Madsen, 1986). Thus, for $T$ 


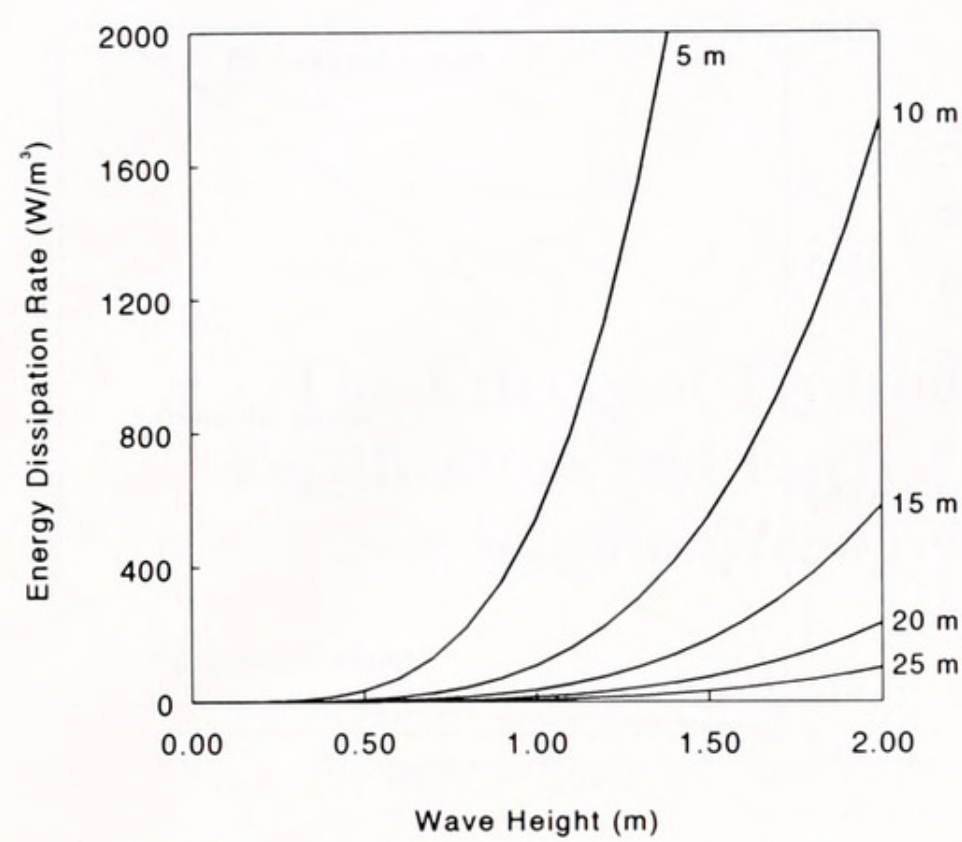

Figure 2. Energy dissipation rates in the benthic boundary layer. Predicted values given typical wave heights and water depths of habitats favored by Strongylocentrotus purpuratus. The wave period is assumed to be $10 \mathrm{~s}$.

$=10 \mathrm{~s}$ and the values of $u_{*}$ assumed here, the boundary layer is expected to be only $0.7 \mathrm{~mm}$ to $4.2 \mathrm{~cm}$ thick. This narrow localization of high energy dissipation rates in the benthic boundary layer is in contrast to the situation in the surf zone, where the entire volume encompassed by the breaking wave is subject to high energy dissipation rates.

In either case, once gametes or embryos leave the surf zone or the benthic boundary layer, they are no longer subject to high energy dissipation rates. Most other marine habitats have turbulent energy dissipation rates that are several orders of magnitude smaller than those found in the surf zone and in the benthic boundary layer. For example, energy dissipation rates in oceanic waters typically vary from $10^{-7}$ to $10^{-1} \mathrm{~W} / \mathrm{m}^{3}$ (Belyaev et al., 1975; Dillon et al., 1981; Kitaigorodskii et al., 1983; Osborn and Lueck, 1985; Baker and Gibson, 1987), and energy dissipation rates in tidally mixed areas vary from $10^{-2}$ to $10^{-1} \mathrm{~W} / \mathrm{m}^{3}$ (Rothschild and Osborn, 1988).

\section{Eddy size}

To visualize how eggs and sperm respond to turbulent flow and understand how it is possible to re-create some of the effects of oceanic turbulence in the laboratory, it is useful to consider the size of the smallest vortices, or eddies, in a flow. This length, called the Kolmogorov length, is

$$
L_{\mathrm{K}}=\left(\frac{v^{3}}{\epsilon}\right)^{1 / 4}
$$

(Tennekes and Lumley, 1972) where $v$ is the fluid's kinematic viscosity $\left(v=\mu / \rho\right.$, approximately $1.2 \times 10^{-6} \mathrm{~m}^{2} / \mathrm{s}$ for seawater at $12{ }^{\circ} \mathrm{C}$ ). For example, using values for $\epsilon$ from 10 to $3000 \mathrm{~W} / \mathrm{m}^{3}$, the Kolmogorov length in the surf zone is predicted to be 22 to $5 \mu \mathrm{m}$. Note that eddy size decreases as the energy dissipation rate increases.

Few eddies have a diameter of less than 5-10 times the Kolmogorov length, and the maximum shear energy density occurs in eddies about 40 times the size of the Kolmogorov length (Lazier and Mann, 1989; Osborn et al., 1990). Therefore, the most energetically significant eddies in the surf zone and benthic boundary layer are 200 to $880 \mu \mathrm{m}$ in diameter, and are larger still in less turbulent flows. Most eddies are thus considerably bigger than a sea urchin egg $(80-110 \mu \mathrm{m})$ and sperm (head, $3 \mu \mathrm{m}$; flagellum, $40-45 \mu \mathrm{m}$ ). Within an eddy, the rotational nature of the flow results in a velocity gradient (a shear) extending from the center of the eddy to its periphery (Vogel, 1981). It is reasonable to suppose, therefore, that the gametes experience turbulent eddies as a temporally variable velocity gradient with an associated shear stress and energy dissipation rate (Denny et al., 1992).

\section{Effects of shear}

As yet, it has not been possible to directly observe eggs and sperm in a velocity gradient of the sort found in the surf zone. Nevertheless, general predictions about their behavior can be made. Like all spherical objects in velocity gradients, eggs are likely to tumble at many cycles per second (Happel and Brenner, 1983; Kessler, 1986; Denny et al., 1992), and the axis of rotation is likely to change rapidly as different eddies shear. The rotation of the eggs induces a secondary velocity gradient (a boundary layer) around the egg. Although sperm are motile, their swimming velocity (about $150-200 \mu \mathrm{m} / \mathrm{s}$; Levitan et al., 1991) is substantially lower than the small-scale velocities induced by turbulence (approximately $u_{*}$; Denny, 1988). Therefore, sperm are also expected to move according to the local water motion. Due to the elongated shape and flexibility of the sperm, however, their motion is expected to differ from that of eggs, and it is possible that the effect of a velocity gradient will be to align sperm with the direction of flow. In the boundary layer surrounding the egg, this alignment would cause sperm to move tangentially to the egg's surface. It is therefore easy to imagine how the induced motion of the egg and sperm might conspire to hinder contact between the gametes.

\section{Shear stress in the laboratory: Taylor-Couette flow}

A simple way to expose eggs and sperm to shear stress (and thereby to mimic one aspect of turbulent flow) is to place them in the well-defined velocity gradient of a Couette cell (Coles, 1965; Donnelly, 1991). Couette cells 
and similar instruments were recently used in several biological investigations. For example, Thomas and Gibson, (1990a,b, 1992) used Couette cells to examine how turbulent motion inhibits dinoflagellate growth, cell count, and chlorophyll content, and Edwards et al. (1989) used a combination of Couette and cone and plate flows to observe changes in cell length, septal length, hyphal diameter, and branching frequency in two species of bacteria.

\section{Materials and Methods}

\section{The Couette cell}

The Couette cell consists of an inner stationary cylinder and a rotating coaxial outer cylinder (Fig. 3). The inner cylinder (50.5-mm outer radius) is constructed of stainless steel with an acrylic plastic base. Cold water circulates through the lumen of the inner cylinder to control the temperature of the test solution, and an air line runs to a small hole at the bottom of the inner cylinder, allowing air to be bubbled into the test solution at a controlled rate. The air bubbles keep the eggs from settling and getting caught between the bases of the two cylinders. The outer cylinder (54-mm inner radius) is made of clear acrylic plastic and has a base that fits onto a motor shaft. The distance between the two cylinders $(3.5 \mathrm{~mm})$ is more than 30 times larger than the diameter of the $S$. purpuratus egg. The cylinders are $20 \mathrm{~cm}$ long, allowing an experimental volume of more than $200 \mathrm{ml}$.

When the motor turns, the outer cylinder rotates, shearing the liquid between the two cylinders. By treating the cylinders as two wide plates a small distance apart, the shear stress $\tau$ in the test solution is calculated to be

$$
\tau=\mu\left(\frac{\omega r}{h}\right)
$$

where $\omega$ is the angular velocity (radians/s) of the outer cylinder and $r$ is its inner radius (here $54 \mathrm{~mm}$ ), $\mu$ is the dynamic viscosity of the test solution, and $h$ is the radial distance between cylinders (here $3.5 \mathrm{~mm}$ ). Equivalently, the flow inside the Couette cell can be described by the energy dissipation rate $\epsilon$ :

$$
\epsilon=\mu\left(\frac{\omega r}{h}\right)^{2}=\frac{\tau^{2}}{\mu}
$$

Note that Equations 3 and 4 hold whether flow in the cell is laminar or turbulent (Schlichting, 1979). Both $\tau$ and $\epsilon$ will be used to describe the flow inside the Couette cell.

By varying $\omega$ (or $\mu$ ) it is possible to recreate the shear stresses (and energy dissipation rates) found in the surf zone. In the experiments described here, filtered seawater was used at $12^{\circ} \mathrm{C}$, and the dynamic viscosity $\mu$ was taken to be $1.24 \times 10^{-3} \mathrm{~Pa} \cdot \mathrm{s}$. The velocity of the outer cylinder

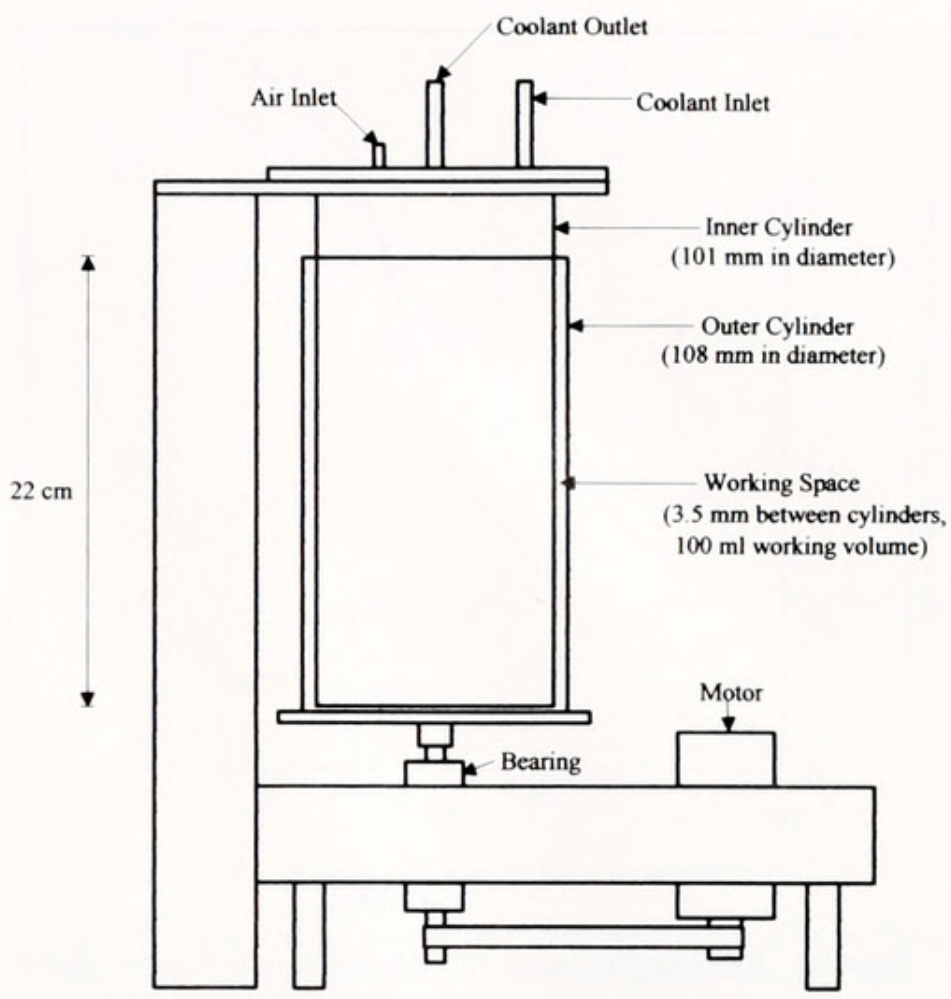

Figure 3. The Couette cell.

was measured by means of a magnetic pickup system. Each time a tooth of a gear attached to the motor shaft passed by the pickup, a current pulse was induced. The pulses were amplified, counted, and converted into angular velocities. The Couette cell was run at shear stresses of 0.06 to $1.45 \mathrm{~Pa}$, corresponding to energy dissipation rates of 2.8 to $1591 \mathrm{~W} / \mathrm{m}^{3}$. These rates cover a large portion of the range of turbulent energy dissipation rates expected on exposed rocky shores.

The Reynolds number describing the flow inside the Couette cell is $\operatorname{Re}=\rho \omega r h / \mu$. At the maximum angular velocity used in this study $(75.4 \mathrm{rad} / \mathrm{s}), \mathrm{Re}=11,600$. Dye studies indicated that flow became turbulent at $\mathrm{Re} \approx 4400$.

\section{Experimental design}

S. purpuratus males and females were induced to spawn by injection with $0.5 \mathrm{M} \mathrm{KCl}$. Sperm were collected and stored undiluted on ice. Eggs (jelly intact) were collected in a beaker filled with filtered seawater, washed three times, and diluted to a $0.5 \%-1 \%$ suspension (by volume), which was stirred gently and kept at $12{ }^{\circ} \mathrm{C}$. Sperm concentrations were determined by hemacytometer counts. All experiments were performed within $8 \mathrm{~h}$ of gamete collection. To determine the relative concentrations of eggs and sperm to be used in each experiment, a standard fertilization curve was created for each pair of urchins (Fig. 4). Small volumes of egg suspension were exposed to so- 


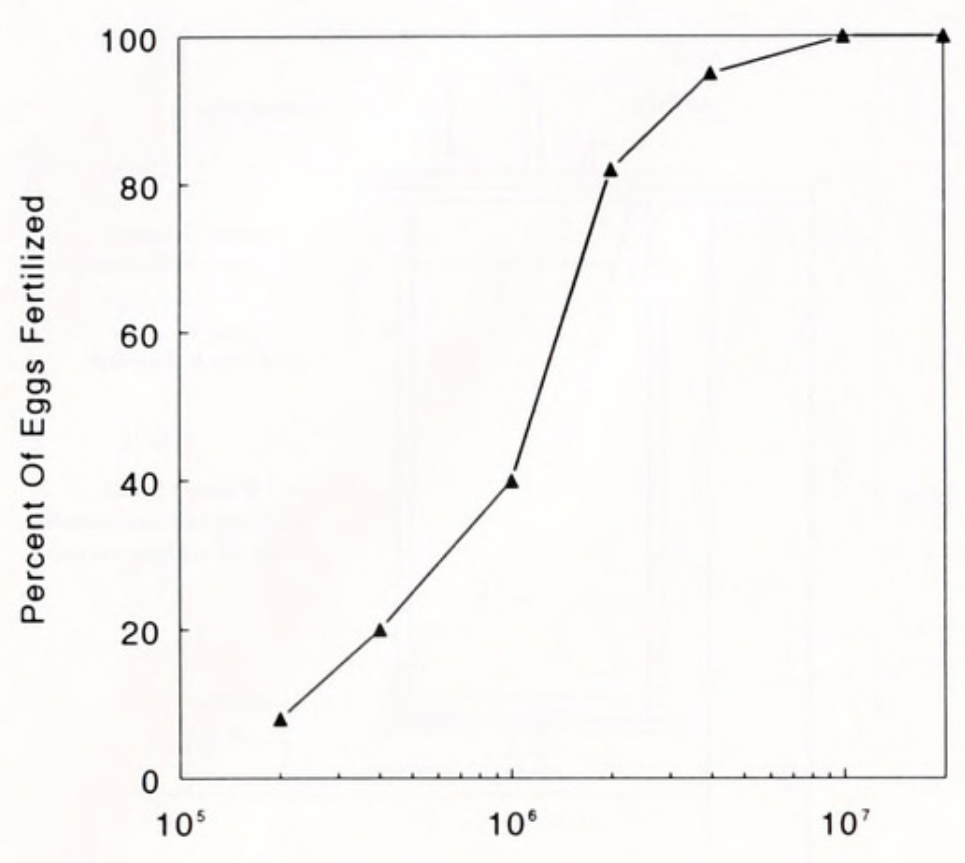

Sperm/mL

Figure 4. Representative standard fertilization curve. Concentrations and volumes of egg and sperm solutions giving $80 \%-90 \%$ fertilization in a test tube were used in all experiments.

lutions of sperm for $2 \mathrm{~min}$ in gently stirred test tubes. Fertilization was stopped by the addition of an equal volume of $0.5 \mathrm{M} \mathrm{KCl}$, which renders the sperm immobile without harming the eggs (Schuel, 1984). Concentrations and relative volumes of eggs and sperm giving rise to $80 \%-$ $90 \%$ fertilization in a test tube were used in the Couette cell experiments, to ensure that the decrease in fertilization success expected as a result of shear stress would not be concealed by an overabundance of sperm.

The rates of energy dissipation used in the experiments ranged from 2.8 to $1591 \mathrm{~W} / \mathrm{m}^{3}$. In each experiment, $45 \mathrm{ml}$ of the egg suspension was put in the Couette cell. The outer cylinder was brought up to speed over about $10 \mathrm{~s}$, after which $5 \mathrm{ml}$ of newly diluted sperm was added to the egg suspension. Fertilization was allowed to take place at the specified energy dissipation rate for $2 \mathrm{~min}$ before the reaction was stopped with $50 \mathrm{ml} 0.5 \mathrm{M} \mathrm{KCl}$. Eggs were subsequently washed with filtered seawater and examined under a microscope $4 \mathrm{~h}$ after fertilization. Because shear stress can induce artificial activation and concomitant formation of both the fertilization envelope and the hyaline membrane (normally indicators of fertilization) in the absence of sperm, only eggs that had divided were counted as fertilized, possibly resulting in a slight underestimate of fertilization. Two hundred eggs were counted per sample.

Each experiment was repeated between 3 and 16 times at the same energy dissipation rates, using gametes from different pairs of urchins. Because the relative concentra- tion and the "fertilizability" of the gametes varied slightly between pairs, all data were normalized to the percent fertilization obtained when the experimental concentrations of eggs and sperm were combined in a test tube in the absence of appreciable shear.

Some urchins, such as those living on exposed rocky shores, experience turbulence almost constantly. Other animals, for instance those in tide pools, may experience significant turbulence only as the waves break, or just when the largest waves break on the shore. To approximate the time-dependent nature of this kind of environmental turbulence more accurately, eggs were fertilized under intermittent shear stress. As above, $45 \mathrm{ml}$ of the egg suspension was put in the Couette cell. Once the outer cylinder had been brought up to speed, $5 \mathrm{ml}$ of newly diluted sperm was added to the egg suspension. Fertilization was allowed to occur for $2 \mathrm{~min}$, during which time the Couette cell was alternately spun for $10 \mathrm{~s}$, then allowed to stop for $10 \mathrm{~s}$ throughout the 2-min trial. Experiments were repeated and data were normalized as above.

To determine if exposure to shear stress decreases fertilization success by damaging gametes (as opposed to some other mechanism, such as interfering with egg-sperm binding), $S$. purpuratus eggs were sheared prior to fertilization and then combined with unsheared, newly diluted sperm in a test tube. Similarly, $S$. purpuratus sperm were sheared prior to fertilization and immediately combined with unsheared eggs in a test tube. Fertilization was stopped after $2 \mathrm{~min}$ by the addition of an equal volume of $0.5 \mathrm{M} \mathrm{KCl}$. For comparison, eggs and sperm from the same animals were fertilized under shear in the Couette cell. All eggs were washed with filtered seawater and incubated at $12^{\circ} \mathrm{C}$ for $4 \mathrm{~h}$ before being examined. Experiments were repeated three times and data were normalized as above.

Eggs were reexamined after $24 \mathrm{~h}$ to determine whether exposure to shear stress (either before or during fertilization) had any effects extending past fertilization. Samples were counted, and the percentage of fertilized eggs that had developed into normal blastulae was recorded. Normal blastulae were characterized as clear, hollow balls of cells spinning rapidly about their animal-vegetal pole axes. Two hundred embryos were counted per sample.

\section{Results}

\section{Fertilization under constant shear stress}

Water motion associated with low energy dissipation rates $\left(<70 \mathrm{~W} / \mathrm{m}^{3}\right)$ enhanced fertilization success, presumably as a result of mixing. As the energy dissipation rate increased from 2.8 to $69.2 \mathrm{~W} / \mathrm{m}^{3}$, the mean fertilization success increased from $78 \%$ to $96 \%$. Fertilization success decreased when fertilization occurred during exposure to moderate and high energy dissipation rates. As 


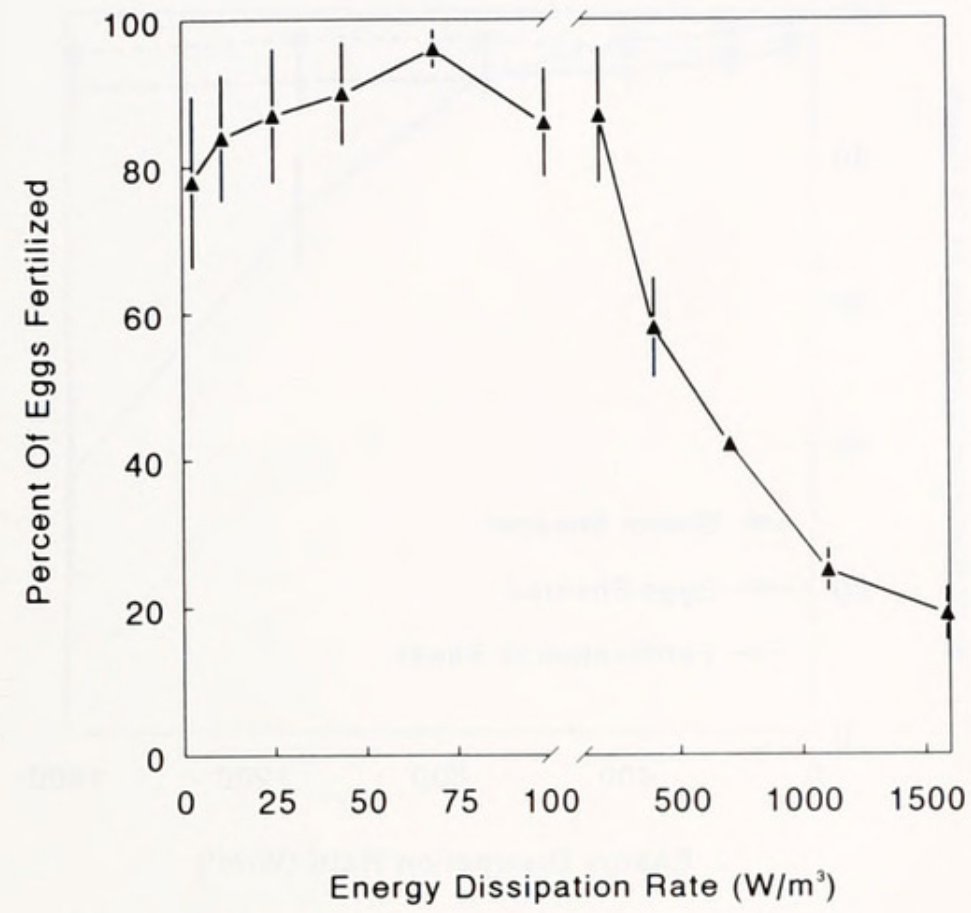

Figure 5. The effect of shear stress on fertilization. Low energy dissipation rates enhance fertilization success, whereas moderate and high energy dissipation rates decrease fertilization success. Data from 16 pairs of sea urchins. Error bars indicate the standard error.

the energy dissipation rate increased from 69.2 to $1591 \mathrm{~W} / \mathrm{m}^{3}$, the percentage of eggs that were fertilized decreased from $96 \%$ to $19 \%$ (Fig. 5).

\section{Intermittent shear stress}

When eggs were fertilized under conditions of intermittent shear stress, fertilization success decreased with increasing energy dissipation rate, although not as dramatically as when the shear stress was constant. As the maximum energy dissipation rate experienced during the 10 -s pulses of turbulence increased from 44.1 to $1591 \mathrm{~W} / \mathrm{m}^{3}$, the mean fertilization success decreased from $90 \%$ to $39 \%$ (Fig. 6). In comparison, when eggs and sperm from the same pair of urchins were fertilized under constant shear, mean fertilization success decreased from $92 \%$ to $19 \%$. At moderate energy dissipation rates (up to $397.7 \mathrm{~W} / \mathrm{m}^{3}$ ), there was no significant difference between the effects of constant and intermittent shear stress. At high energy dissipation rates $\left(707 \mathrm{~W} / \mathrm{m}^{3}\right.$ and above), eggs fertilized under intermittent shear stress had greater fertilization success than eggs fertilized under constant shear.

In this set of experiments, few measurements were made at low energy dissipation rates. Therefore, the pattern seen in constant shear stress of an increase in fertilization success at low energy dissipation rates was not observed.

\section{Shearing gametes before fertilization}

When $S$. purpuratus eggs and sperm were sheared separately before fertilization and then combined with un-

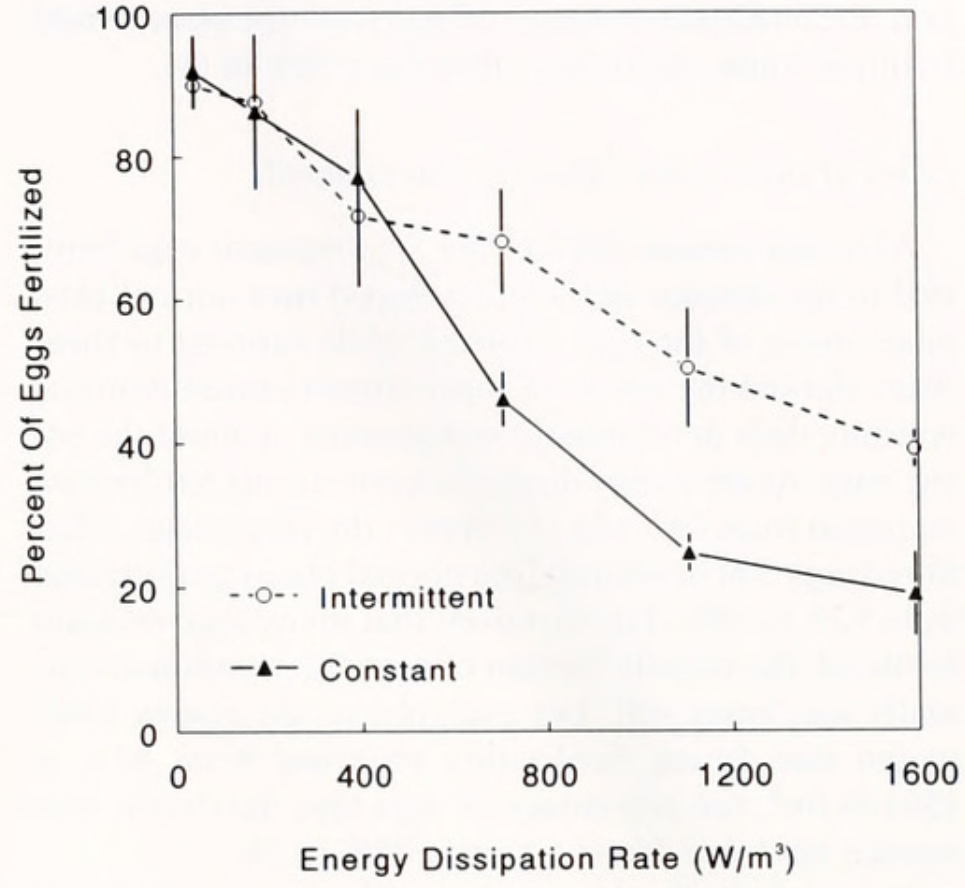

Figure 6. The effect of intermittent shear stress on fertilization. Data are from three pairs of sea urchins. Error bars indicate standard error.

sheared gametes in a test tube in the absence of appreciable shear stress, fertilization success was very high. As the energy dissipation rate increased from 44.1 to $1591 \mathrm{~W} / \mathrm{m}^{3}$, the fertilizability of the sheared eggs decreased from $98 \%$ to $86 \%$, and the fertilizability of the sheared sperm decreased from $100 \%$ to $92 \%$ (Fig. 7). In compar-

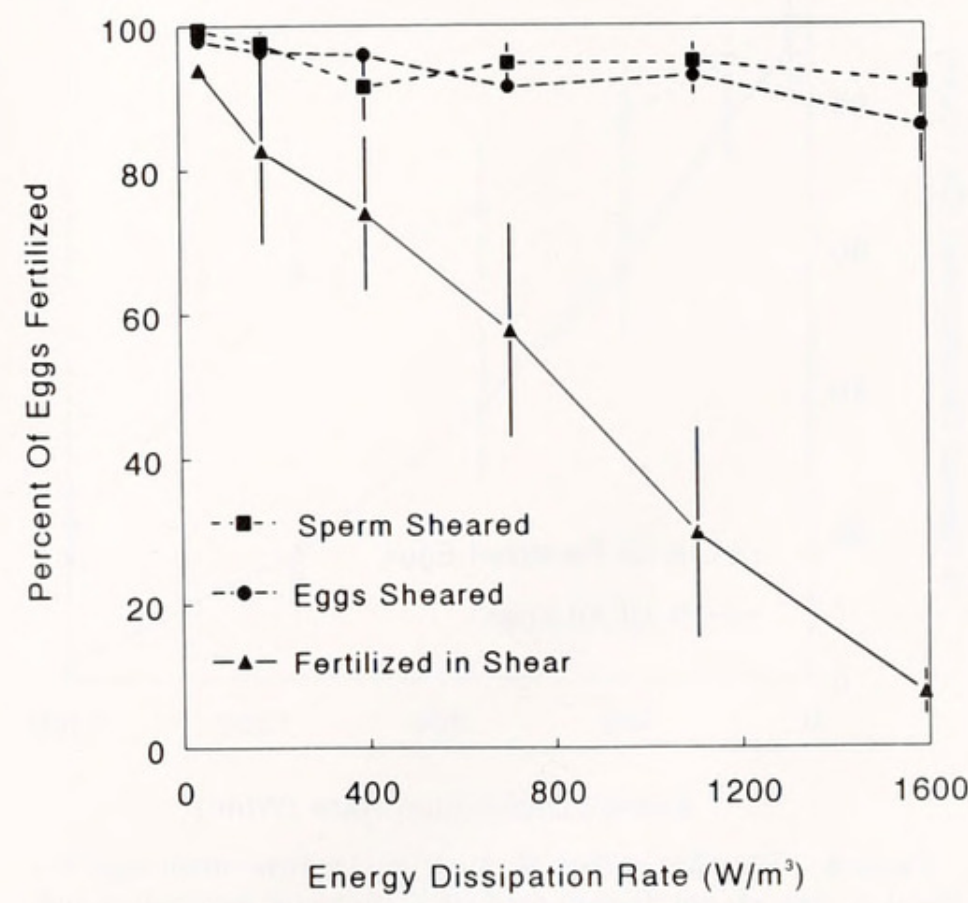

Figure 7. The fertilizability of presheared gametes. Sperm and eggs lose little fertilizability when sheared before fertilization. Data are from three pairs of sea urchins. Error bars indicate standard error. 
ison, the fertilization success of eggs from the same female fertilized under shear decreased from $94 \%$ to $8 \%$.

\section{Effect of shear stress on early development}

Although almost $100 \%$ of the S. purpuratus eggs fertilized in the absence of shear developed into normal blastulae, many of the eggs fertilized while exposed to shear stress showed the effects of shear-stress-induced damage; typically their development was arrested at about the 64cell stage. As the energy dissipation rate during fertilization increased from 44.1 to $1591 \mathrm{~W} / \mathrm{m}^{3}$, the percentage of fertilized eggs that developed into normal blastulae decreased from $92 \%$ to $22 \%$ (Fig. 8). Given that many eggs were not fertilized, the overall fraction of eggs that developed normally was lower still. For example, as the energy dissipation rate during fertilization increased from 44.1 to $1591 \mathrm{~W} / \mathrm{m}^{3}$, the percentage of eggs that developed into normal blastulae decreased from $88 \%$ to $2 \%$.

In comparison, almost all fertilized eggs developed normally when the gametes were sheared separately and then combined in a test tube (Fig. 9A). As the energy dissipation rate increased from 44.1 to $1591 \mathrm{~W} / \mathrm{m}^{3}$, the percentage of sheared eggs that (once fertilized) developed into normal blastulae decreased only from $99 \%$ to $89 \%$, and the percentage of eggs fertilized by sheared sperm that developed into normal blastulae decreased only from $96 \%$ to $94 \%$. These data can be graphed to reflect the total

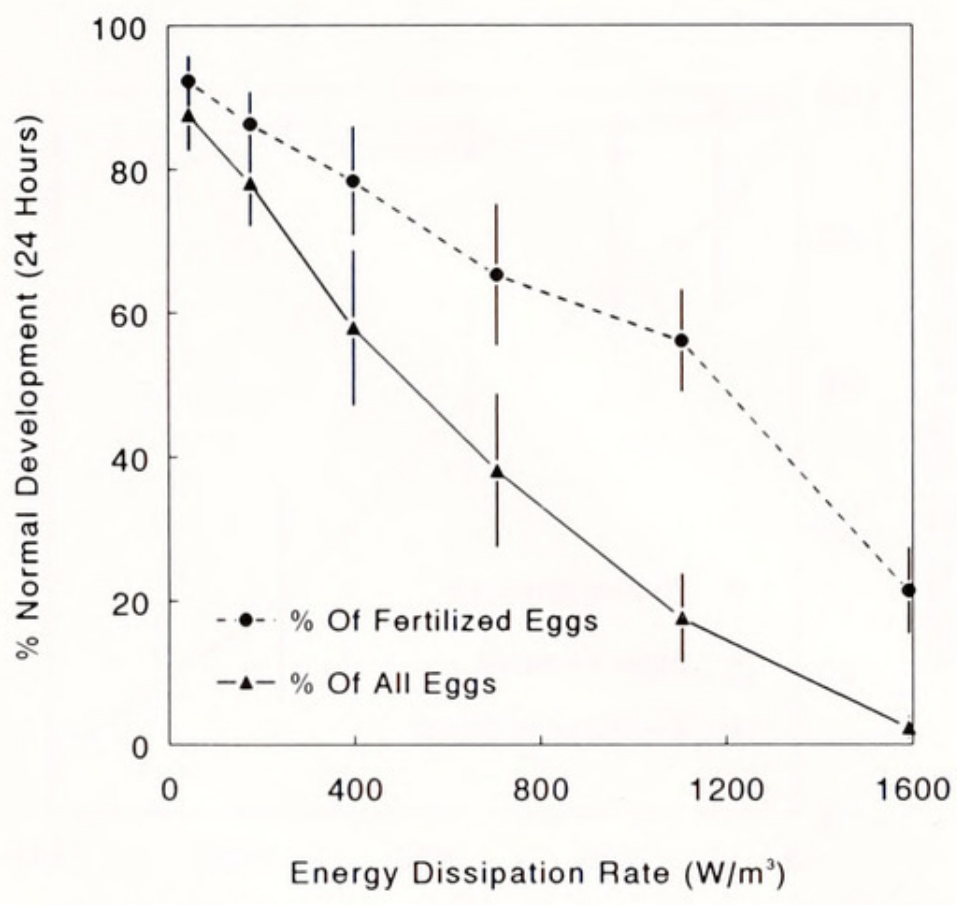

Figure 8. The effect of shear stress on development. Many eggs fertilized in shear do not develop normally. Combining fertilization and developmental data shows that the percentage of all eggs developing normally at $24 \mathrm{~h}$ is very low. Data are from 12 pairs of urchins. Error bars indicate standard error.
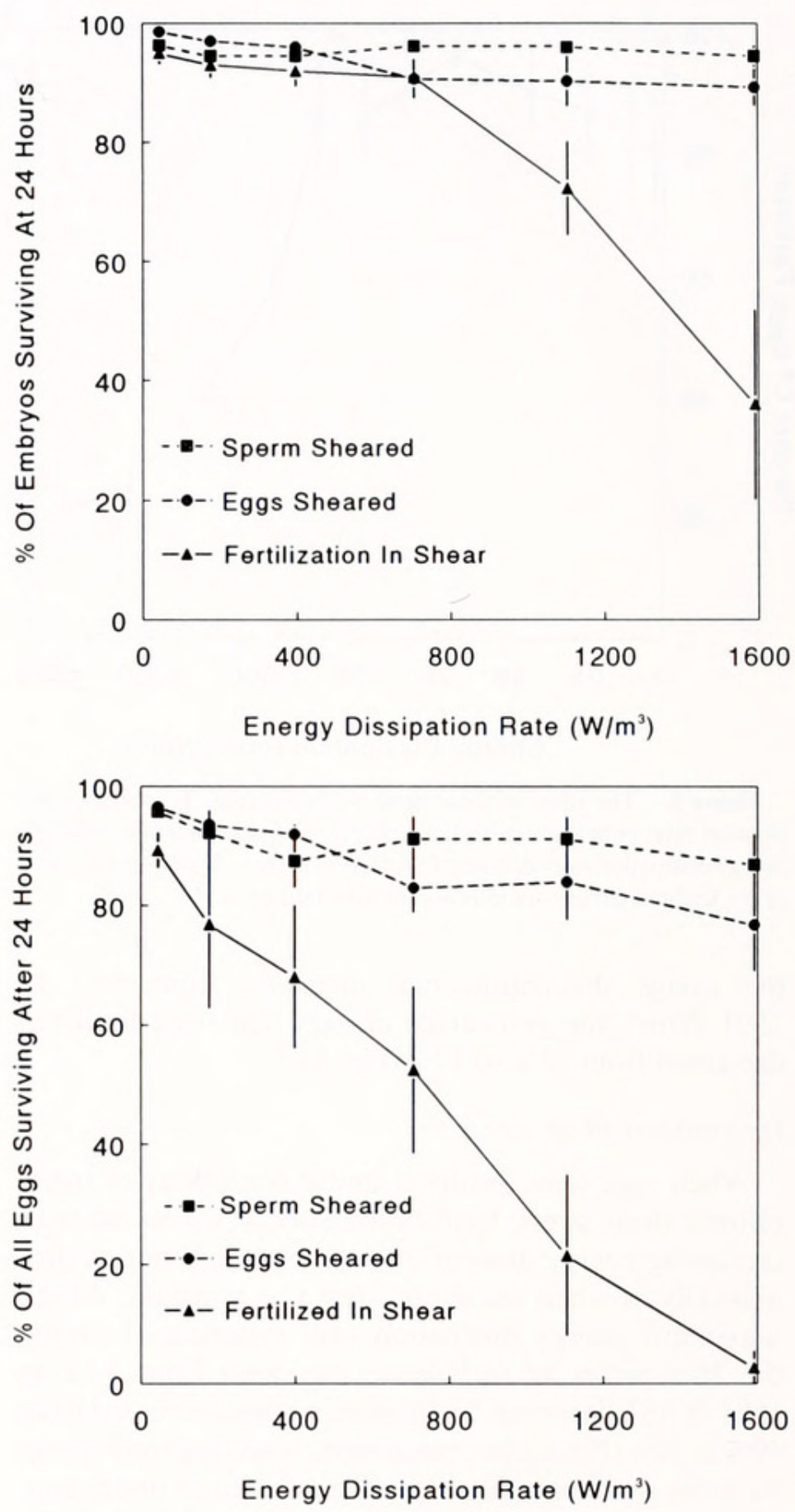

Figure 9. The effect of shearing gametes on early development. Almost all eggs fertilized in the absence of shear develop into normal blastulae, but eggs fertilized in shear do not. (A) Development of fertilized eggs. (B) Survival of all eggs to blastula, including eggs that were not successfully fertilized. Data are from three pairs of urchins. Error bars indicate standard error.

number of eggs that developed into normal blastulae, including the effect of reduced fertilization (Fig. 9B). As the energy dissipation rate increased from 44.1 to $1591 \mathrm{~W} / \mathrm{m}^{3}$, the percentage of sheared eggs that developed into normal blastulae decreased from $97 \%$ to $77 \%$, and the percentage of eggs fertilized by sheared sperm that developed into normal blastulae decreased only from $96 \%$ to $87 \%$. 


\section{Discussion}

\section{How can low levels of turbulence increase fertilization} success?

Although intense turbulence limits fertilization success, low energy dissipation rates enhance fertilization success. This is presumably because turbulent mixing increases contact rates between the egg and sperm. It is reasonable to suppose that at low turbulent intensities the tumbling of the egg in response to shifting velocity gradients may not be rapid or abrupt enough to inhibit binding of the sperm to the egg. Similarly, investigators have shown that low energy dissipation rates increase rates of contact between predator and prey in the plankton (Rothschild and Osborn, 1988; Marrasé et al., 1990; Costello et al., 1990; Saiz et al., 1992). At high energy dissipation rates, the beneficial aspects of turbulence are outweighed by other factors.

\section{Why does excessive turbulence decrease fertilization success?}

Despite observations that turbulence decreases fertilization success by diluting gamete concentration, the data presented above indicate that environmentally relevant turbulence can dramatically decrease fertilization success even when eggs and sperm are in high concentrations. There are several possible mechanisms for this shear-induced decrease in fertilization success, including gamete damage, a decrease in the encounter rate between egg and sperm, and a removal of sperm from the egg's surface during the latent period, the period after the sperm has made initial contact with the egg, but before fertilization is complete. The fact that shearing gametes before fertilization does not dramatically reduce their fertilizability indicates that exposure to shear does not substantially damage gametes (Fig. 7). This suggests that high levels of turbulence instead may limit fertilization by reducing the effective encounter rate between gametes. If, as expected, turbulence causes the eggs to tumble rapidly and the sperm to align themselves in the direction of flow tangential to the egg surface, small-scale turbulence could hinder contact between the gametes. Alternatively (or additionally), exposure to turbulence might limit the ability of the sperm to attach to an egg once contact has been made, or it might cause attached sperm to be removed before fertilization is complete.

Our experiments provide no direct evidence that allows us to choose among these possibilities, but indirect evidence allows for reasonable speculation. We begin by asking whether it is likely that hydrodynamic shear stresses are sufficient to tear an attached sperm from an egg. Although no data are yet available for sea urchins, bond strengths between a sperm and the zona pellucida of an egg range in mammalian systems from 6 to 250 dyn, with 40 dyn being the most likely average value (Baltz et al., 1988), and for the sake of argument we assume a similar value for urchin sperm. This force can be compared to the hydrodynamic force exerted on an urchin sperm as follows: The shear force pulling at a sperm attached to an egg is approximately equal to the hydrodynamic shear stress to which the sperm is exposed multiplied by the sperm's surface area. If a sea urchin sperm is modeled as a $41-\mu \mathrm{m}$-long cylinder with a radius of $0.1 \mu \mathrm{m}$ (the flagellum) attached to a conical head with a height of $3 \mu \mathrm{m}$ and a radius of $0.5 \mu \mathrm{m}$ (Gray, 1955; Brokaw, 1965), its surface area is $31.4 \mu \mathrm{m}^{2}$. At a shear stress of $1.45 \mathrm{~Pa}$ (the maximum shear stress to which the gametes were exposed in the Couette cell, equivalent to an energy dissipation rate of $1591 \mathrm{~W} / \mathrm{m}^{3}$ ) the resulting shear force is $4.6 \mathrm{dyn}$, much less than the expected bond strength. A still smaller force would be exerted at lower shear stresses. It thus seems unlikely that sperm, once well attached, are sheared off before fertilization is complete. This suggests that the primary effect of hydrodynamic shear on fertilization is to reduce the encounter rate between gametes, to disrupt contact between sperm and egg before final sperm attachment, or both.

This proposition is supported by our experiment regarding the "dose" of turbulence to which gametes are subjected. A comparison of the effects of constant and intermittent shear stress reveals a time-dependent response. At high shear stresses, a smaller percentage of eggs is fertilized if shear is constant than if shear is applied in 10 -s periods alternating with 10 -s periods of quiescence (Fig. 6). In both cases gametes are exposed to the same peak shear stress. If shear stress acted primarily by tearing well-attached sperm from the egg before they could fertilize (a process that takes about 20-30 s [Epel, 1989, 1990; Ruiz-Bravo and Lennarz, 1989]), one would expect that the effects of intermittent shear would be similar to those of constant shear. If, on the other hand, the primary effect of shear stress is to prevent sperm from encountering or becoming strongly attached to eggs (processes that can occur effectively in periods less than $10 \mathrm{~s}$ [Epel, 1989, 1990; Ruiz-Bravo and Lennarz, 1989]), periods of quiescence would allow some sperm to encounter eggs and attach well enough to be immune from later disruption by shear stress. If this is indeed the case, fertilization rates will be higher under intermittent shear, and this is the effect that we observed. The time-dependence of the effect of shear stress is consistent with the hypothesis that shear stress limits fertilization by interfering with contact between the egg and sperm.

Further experiments will be necessary to test this speculation and to differentiate between the effects of turbulence on encounter rates and the effects on subsequent adhesion. 


\section{Why does turbulence affect development?}

Only a fraction of the eggs that are fertilized under turbulent conditions develop into normal blastulae (Fig. 8), indicating that shear stress, whether constant or intermittent, affects reproductive success beyond fertilization. Somehow, exposure to shear stress curtails or irrevocably alters some process essential to normal development. Although the mechanism or mechanisms behind this effect are uncertain, reasonable speculation is again possible. Hiramoto (1974) noted a brief fivefold stiffening of the egg membrane $90 \mathrm{~s}$ after fertilization in the urchin Temnopleurus toreumaticus. If $S$. purpuratus eggs experience a similar increase in stiffness, and if the hardened membranes result in increased damage, eggs exposed to shear stress during fertilization could sustain injuries not seen when eggs were exposed to shear stress prior to fertilization. These injuries could result in leakage of some essential cytoplasmic compound or in infection, either of which could prevent the fertilized egg from completing more than a few rounds of cell division.

Not only might different types or degrees of injury arise, depending on whether the egg is exposed to turbulence before or during fertilization, but the ability of the egg to heal itself after injury might vary. Mechanically injured cells heal themselves by releasing exocytotic vesicles, which fuse to the plasma membrane (Steinhardt et al., 1994). Shortly after fertilization, these vesicles are depleted (Vacquier, 1981), presumably decreasing the cell's ability to heal itself. This could help explain why a large fraction of the eggs fertilized under turbulent conditions developed abnormally.

Two further possibilities can be discounted. First, injuries resulting in parthenogenic stimulation or polyspermy cannot explain the effect of shear stress on development, because the fertilized eggs usually divide to about the 64-cell stage before degrading. In contrast, artificially activated sea urchin eggs tend not to divide, and polyspermic eggs have very characteristic disruptions in their cleavage patterns (e.g., irregular or incomplete division, multiple asters, lobe formation), none of which were observed here. Second, if exposure to shear stress altered egg membranes in some way, eggs sheared prior to fertilization would show the same defects in their development, and this was not seen.

\section{Ecological implications of the effect of turbulence on fertilization}

These experiments indicate that although low levels of shear stress can aid mixing and fertilization, the intense shear stress found in the surf zone and in the benthic boundary layer can have severe mechanical effects on fertilization and early development. These effects interact with those of gamete dilution to narrow any window of opportunity open to urchins attempting to reproduce by external fertilization. For instance, although surge channels may restrict gamete dilution (Denny et al., 1992), thereby promoting efficient fertilization, the deleterious effects of shear stress may still limit the fraction of eggs fertilized. Furthermore, any eggs that are fertilized are very likely to develop abnormally. Gametes shed outside of surge channels may be quickly swept out of the surf zone, thereby avoiding prolonged exposure to high shear stresses, but dilution will be rapid; consequently, the fraction of eggs fertilized will again be low. Similarly, while gametes released above the benthic boundary layer (by large or aggregated individuals) experience lower energy dissipation rates, they too are quickly diluted, and fertilization rates will still be low.

The picture is not quite as bleak as it appears. Turbulence is patchy, and even areas with high temporally averaged rates of energy dissipation may experience (short) periods of relative calm. Because of their great fecundity, urchins able to time it right may end up with abundant offspring.

There are plenty of sea urchins along our rocky shores, but the chanciness of external fertilization in a turbulent environment suggests that only a small number of them contribute to the next generation. If this is true, then the effective population is much smaller than the actual population - a situation that could have populational, conservational, and evolutionary consequences (Quinn et al., 1993; Hedgecock, 1994).

\section{Acknowledgments}

We thank D. Epel for his constant moral and technical support and for his excellent advice. Both he and Friday Harbor Laboratories (University of Washington) provided generous access to laboratory facilities. H. Crenshaw made helpful suggestions, and B. Rees, P. Sund, J. Geller, and B. Podolsky made insightful comments on earlier versions of this manuscript. Two anonymous reviewers had thoughtful observations and helped clarify parts of the paper. This study was funded by grants to K. Mead from the Myers Oceanographic and Marine Biological Trust, and by NSF grants to M. Denny (OCE-9115688) and D. Epel (IBN-9205393).

\section{Literature Cited}

Babcock, R. C., and C. N. Mundy. 1992. Reproductive biology, spawning, and field fertilization rates of Acanthaster planci. Aust. J. Mar. Freshwater Res. 43: 525-534.

Babcock, R. C., C. N. Mundy, and D. Whitehead. 1994. Sperm diffusion models and in situ confirmation of long-distance fertilization in the free-spawning asteroid Acanthaster planci. Biol. Bull. 186: 17-28.

Baltz, J. M., D. F. Katz, and R. A. Cone. 1988. Mechanics of spermegg interaction at the zona pellucida. Biophys. J. 54: 643-654. 
Baker, M. A., and C. H. Gibson. 1987. Sampling turbulence in the stratified ocean: statistical consequences of strong intermittency. $J$. Phys. Ocean. 17: 1817-1856.

Belyaev, V.S., M. M. Lubimtzev, and R. V. Ozmidov. 1975. The rate of dissipation of turbulent energy in the upper layer of the ocean. J. Phys. Ocean 5: 499-505.

Brokaw, C. J. 1965. Non-sinusoidal bending waves of sperm flagella. J. Exp. Biol. 43: 155-169.

Coles, D. 1965. Transition in circular Couette flow. J. Fluid Mech. 21: $385-425$.

Costello, J. H., J. R. Strickler, C. Marrasé, G. Trager, R. Zeller, and A. J. Friese. 1990. Grazing in a turbulent environment: Behavioral response of a calanoid copepod, Centropages hamatus. Proc. Natl. Acad. Sci. 87: 1648-1652.

Denny, M. W. 1988. Biology and the Mechanics of the Wave-Swept Environment. Princeton University Press, Princeton, NJ. 329 pp.

Denny, M., and M. Shibata. 1989. Consequences of surf-zone turbulence for settlement and external fertilization. Am. Nat. 134: 859889

Denny, M., J. Dairiki, and S. Distefano. 1992. Biological consequences of topography on wave-swept rocky shores: I. Enhancement of external fertilization. Biol. Bull. 183: 220-232.

Dillon, T. M., J. G. Richman, C. G. Hansen, and M. D. Pearson. 1981. Near-surface turbulence measurements in a lake. Nature 290: 390-392.

Donnelly, R. J. 1991. Taylor-Couette flow: The early days. Physics Today 44: 32-39.

Edwards, N., S. Beeton, A. T. Bull, and J. C. Merchuk. 1989. A novel device for the assessment of shear effects on suspended microbial cultures. Appl. Microbiol. Biotechnol. 30: 190-195.

Epel, D. 1989. Arousal of activity in sea urchin eggs at fertilization. Chapter 15 in The Cell Biology of Fertilization, H. Schatten and G. Schatten, eds. Academic Press, San Diego. 404 pp

Epel, D. 1990. The initiation of development at fertilization. Cell Differ. Dev. 29: $1-12$.

Fischer, H. B. 1979. Mixing in Inland and Coastal Waterways. Academic Press, New York. 483 pp.

George, R., R. E. Flick, and T. Guza. 1994. Observations of turbulence in the surf zone. J. Geophys. Res. 99: 801-810

Grant, W. D., and O. S. Madsen. 1986. The continental-shelf bottom boundary layer. Ann. Rev. Fluid. Mech. 18: 265-305.

Gray, J. 1955. The movement of sea-urchin spermatozoa. J. Exp. Biol. 32: $775-801$.

Grosberg, R. K. 1987. Limited dispersal and proximity-dependent mating success in the colonial ascidian Botryllus schlosseri. Evolution 41: $372-384$

Grosberg, R. K. 1991. Sperm-mediated gene flow and the genetic structure of a population of the colonial ascidian Botryllus schlosseri. Evolution 45: 130-142.

Happel, J., and H. Brenner. 1983. Low Reynolds Number Hydrodynamics. Martinus Nijhoff Publishers, Dordrecht. 553 pp

Hedgecock, D. 1994. Does variance in reproductive success limit effective population sizes of marine organisms? Pp. 122-143 in Genetics and Evolution of Aquatic Organisms, A. R. Beaumont, ed. Chapman and Hall, London

Hiramoto, Y. 1974. Mechanical properties of the surface of the sea urchin egg at fertilization and during cleavage. Exp. Cell Res. 89: $320-326$

Kessler, J. O. 1986. The external dynamics of swimming micro-organisms. Pp. 257-307 in Progress in Phycological Research, Vol. 4, F. E. Round and D. J. Chapman, eds. Biopress Ltd, Bristol. 481 pp.

Kitaigorodskii, S. A., M. A. Donelan, J. L. Lumley, and E. A. Terray. 1983. Wave-turbulence interactions in the upper ocean. Part II: Statistical characteristics of wave and turbulent components of the random velocity field in the marine surface layer. J. Phys. Ocean 13: 1988-1999

Lazier, J. R. N., and K. H. Mann. 1989. Turbulence and the diffusive layers around small organisms. Deep-Sea Res. 36: 1721-1733.

Levitan, D. R. 1991. Influence of body size and population density on fertilization success and reproductive output in a free-spawning invertebrate. Biol. Bull. 181: 261-268.

Levitan, D. R., M. A. Sewell, and F.-S. Chia. 1991. Kinetics of fertilization in the sea urchin Strongylocentrotus franciscanus: interaction of gamete dilution, age, and contact time. Biol. Bull. 181: 371-378.

Levitan, D. R., M. A. Sewell, and F.-S. Chia. 1992. How distribution and abundance influence fertilization success in the sea urchin Strongylocentrotus franciscanus. Ecology 73: 248-254

Marrasé, C., J. H. Costello, T. Granata, and J. R. Strickler. 1990. Grazing in a turbulent environment: energy dissipation, encounter rates, and efficacy of feeding currents in Centropages hamatus. Proc. Natl. Acad. Sci. 87: 1653-1657.

Middleton, G. V., and J. B. Southard. 1984. Mechanics of Sediment Movement. Society of Economic Paleontologists and Mineralogists, Tulsa, Oklahoma. $401 \mathrm{pp}$

Okubo, A. 1978. Horizontal dispersion and critical scales for phytoplankton patches. Pp. 1-42 in Spatial Pattern in Plankton Communities, from the NATO Conference on Marine Biology. Erice, Italy, 1977. J. H. Steele, ed. Plenum Press, New York. 470 pp

Oliver, J., and R. Babcock. 1992. Aspects of the fertilization ecology of broadcast spawning corals: sperm dilution effects and in situ measurements of fertilization. Biol. Bull. 183: 409-417.

Osborn, T. R., and R. G. Lueck. 1985. Turbulence measurements with a submarine. J. Phys. Ocean. 15: 1502-1520.

Osborn, T. R., H. Yamazaki, and K. Squires. 1990. Direct simulation of the effect of turbulence on planktonic contact rates. Pp. 99-103 in Large Marine Ecosystems: Patterns, Processes, and Yields. $\mathrm{K}$ Sherman, L. M. Alexander, and B. D. Gold, eds. Publication 90$30 \mathrm{~S}$ of the American Association for the Advancement of Science. Washington, DC. $242 \mathrm{pp}$

Pennington, J. T. 1985. The ecology of fertilization of echinoid eggs: the consequences of sperm dilution, adult aggregation, and synchronous spawning. Biol. Bull. 169: 417-430.

Petersen, C. W. 1991. Variation in fertilization rate in the tropical reef fish. Halichoeres bivattatus: correlates and implications. Biol. Bull. 181: $232-237$

Petersen, C. W., R. R. Warner, S. Cohen, H. C. Hess, and A. T. Sewell. 1992. Variable pelagic fertilization success: implications for mate choice and spatial patterns of mating. Ecology 73: 391-401

Quinn, J. F., S. R. Wing, and L. W. Botsford. 1993. Harvest refugia in marine invertebrate fisheries: models and applications to the red sea urchin, Strongylocentrotus franciscanus. Am. Zool. 33: 537-550.

Rothschild, B. J., and T. R. Osborn. 1988. Small-scale turbulence and plankton contact rates. J. Plank. Res. 10: 465-474

Ruiz-Bravo, N., and W. J. Lennarz. 1989. Receptors and membrane interactions during fertilization. Chapter 2 in The Molecular Biology of Fertilization. H. Schatten and G. Schatten, eds. Academic Press San Diego. 384 pp

Saiz, E., M. Alcaraz, and G.-A. Paffenhöfer. 1992. Effects of smallscale turbulence on feeding rate and gross-growth efficiency of three Acartia species (Copepoda: Calanoida). J. Plank. Res. 14: 10851097

Schlichting, H. 1987. Boundary-Layer Theory. 7th ed. McGraw-Hill, New York. 817 pp

Schuel, H. 1984. The prevention of polyspermic fertilization in sea urchins. Biol. Bull. 167: 271-309.

Sewell, M. A., and D. R. Levitan. 1992. Fertilization success during a natural spawning of the dendrochirote sea cucumber Cucumaria miniata. Bull. Mar. Sci. 51: 161-166. 
Steinhardt, R. A., B. Guoqiang, and J. M. Alderton. 1994. Cell membrane resealing by a vesicular mechanism similar to neurotransmitter release. Science 263: 390-393.

Svendsen, I. A. 1987. Analysis of surf zone turbulence. J. Geophys Res. 92: 5115-5124.

Tennekes, H., and J. L. Lumley. 1972. A First Course in Turbulence. MIT Press, Cambridge. 300 pp.

Thomas, W. H., and C. H. Gibson. 1990a. Effects of small-scale turbulence on microalgae. J. Appl. Phycol. 2: 71-77.

Thomas, W. H., and C. H. Gibson. 1990b. Quantified small-scale turbulence inhibits a red tide dinoflagellate, Gonyaulax polyedra Stein. Deep-Sea Res. 37: 1583-1593.

Thomas, W. H., and C. H. Gibson. 1992. Effects of quantified small- scale turbulence on the dinoflagellate, Gymnodinium sanguineum (splendens): contrasts with Gonyaulax (Lingulodinium) polyedra. and the fishery implication. Deep-Sea Res. 39: 1429-1437.

Thornton, E. B., and R. T. Guza. 1983. Transformation of wave height distribution. J. Geophys. Res. 88: 5925-5938.

Vacquier, V. D. 1981. Dynamic changes of the egg cortex. Dev. Biol. 84: $1-26$

Vogel, S. 1981. Life in Moving Fluids. Princeton University Press, Princeton, NJ. 352 pp.

Vogel, H., G. Chizak, P. Chang, and P. Wolf. 1982. Fertilization kinetics of sea urchin eggs. Math. Biosci. 58: 189-216.

Yund, P. O. 1990. An in situ measurement of sperm dispersal in a colonial marine hydroid. J. Exp. Zoo. 253: 102-106. 


\section{$2 \mathrm{BHL}$ Biodiversity Heritage Library}

Mead, K S and Denny, Mark W. 1995. "The Effects of Hydrodynamic Shear Stress on Fertilization and Early Development of the Purple Sea Urchin Strongylocentrotus purpuratus." The Biological bulletin 188, 46-56. https://doi.org/10.2307/1542066.

View This Item Online: https://www.biodiversitylibrary.org/item/17201

DOI: https://doi.org/10.2307/1542066

Permalink: https://www.biodiversitylibrary.org/partpdf/8067

\section{Holding Institution}

MBLWHOI Library

\section{Sponsored by}

MBLWHOI Library

\section{Copyright \& Reuse}

Copyright Status: In copyright. Digitized with the permission of the rights holder.

License: http://creativecommons.org/licenses/by-nc-sa/3.0/

Rights: https://biodiversitylibrary.org/permissions

This document was created from content at the Biodiversity Heritage Library, the world's largest open access digital library for biodiversity literature and archives. Visit BHL at https://www.biodiversitylibrary.org. 